\title{
Sites of origin in the central nervous system of monoamine metabolites measured in human cerebrospinal fluid ${ }^{1}$
}

\author{
E. GARELIS AND T. L. SOURKES \\ From the Laboratory of Chemical Neurobiology, Department of Psychiatry, \\ McGill University, Montreal, Quebec, Canada
}

SUMMARY The concentrations of homovanillic acid (HVA) and 5-hydroxyindole-acetic acid (5-HIAA) were measured in five cases with partial or complete block of CSF circulation, at various levels. Determinations were made in both a lumbar and a cisternal, or 'mixed', sample obtained during pneumoencephalography. Most of the HVA appears to enter the ventricular system at the lateral ventricles, whereas much of the 5-HIAA in CSF originates in lower neuronal structures, including the spinal cord. The spinal contribution to the 5-HIAA content of lumbar CSF is of the order of $23-37 \%$.

Measurement of monoamine metabolites in the cerebrospinal fluid (CSF) is an increasingly important approach to the problem of clarifying the role of biogenic amines in various neurological and psychiatric diseases (Moir, Ashcroft, Crawford, Eccleston, and Guldberg, 1970; Roos, 1971; Bowers, 1972). It has also been suggested that these metabolites might serve as diagnostic tools in certain conditions (Andersson and Roos, 1969; Curzon, Gumbert, and Sharpe, 1971). Homovanillic acid (HVA) and 5-hydroxyindoleacetic acid (5-HIAA), the major terminal metabolites of dopamine and serotonin, respectively, are the compounds usually measured.

Most of the clinical studies, particularly those on psychiatric patients, have used fluid obtained by lumbar puncture on the assumption that monoamine metabolites at this level would reflect the state of the parent amines in the brain. This assumption, however, has recently been challenged by findings in experimental animals (Bulat and Živcović, 1971) and in certain clinical cases with partial spinal blocks (Curzon et al., 1971). These results suggest that 5-HIAA in the spinal fluid comes mainly from the adjacent

\footnotetext{
1 This investigation received financial support from the World Health Organization, through a grant to E. Garelis, and from the Medical Research Council (Canada) through a grant to T. L. Sourkes.
}

regions of the spinal cord, whereas HVA is formed exclusively at higher levels in the central nervous system (CNS).

In the course of a more general project to study the levels ofHVA and 5-HIAA in different compartments of CSF and the effect of various factors on their concentrations, we studied five cases with blockage of CSF circulation in different regions. One patient had a complete spinal block, but the other four were being investigated by pneumoencephalography (PEG). This technique not only provides valuable information about the state of the brain and the various CSF compartments but also permits direct comparison of the concentrations of HVA and 5-HIAA in the lumbar CSF and in CSF corresponding to a 'higher' level. The higher level involved is difficult to specify exactly because the injection of air produces mixing of the fluid from various compartments (Moir et al., 1970; Garelis and Sourkes, unpublished).

\section{METHODS}

Four cases undergoing diagnostic PEG at the Montreal Neurological Hospital, and found to have complete or partial block in CSF circulation, were included in the present study. PEG was performed 
TABLE 1

CONCENTRATIONS OF HVA AND 5-HIAA (ng/ml.) IN LUMBAR AND 'MIXED' OR CISTERNAL CSF IN CASES WITH OBSTRUCTION OF CSF CIRCULATION

\begin{tabular}{|c|c|c|c|c|c|c|}
\hline \multirow[t]{2}{*}{ Cases } & \multirow[t]{2}{*}{ Diagnosis } & \multirow[t]{2}{*}{ Site and degree of block } & \multicolumn{2}{|c|}{$H V A(n g / m l)}$. & \multicolumn{2}{|c|}{ 5-HIAA (ng/ml.) } \\
\hline & & & Lumbar & Mixed & Lumbar & Mixed \\
\hline 1 & Paraventricular gliosis & $\begin{array}{l}\text { Complete block of both fora- } \\
\text { mina of Monro }\end{array}$ & 19 & $<10$ & 26 & 35 \\
\hline 2 & $\begin{array}{l}\text { Hydrocephalus due to ob- } \\
\text { structed ventriculoatrial } \\
\text { shunt }\end{array}$ & $\begin{array}{l}\text { Complete block between } \\
\text { ventricular-subarachnoid } \\
\text { compartments of the brain }\end{array}$ & 177 & 266 & 83 & 106 \\
\hline 3 & $\begin{array}{l}\text { Possible hydromyelia } \\
\quad \text { (syringomyelia) } C_{1}-C_{5}\end{array}$ & $\begin{array}{l}\text { Possible partial obstruction be- } \\
\text { tween 4th ventricle-cisterna } \\
\text { magna }\end{array}$ & 20 & 73 & 21 & 43 \\
\hline $\begin{array}{l}4 \\
5\end{array}$ & $\begin{array}{l}\text { Metastatic carcinoma } \\
\text { Metastatic carcinoma } \\
\quad \text { (extradural) }\end{array}$ & $\begin{array}{l}\text { Partial blocks } T_{1}, T_{3}, T_{8} \\
\text { Complete block } T_{2}-T_{3}\end{array}$ & $<10$ & $\begin{array}{c}57 \\
188 \\
\text { (cisternal) }\end{array}$ & $\begin{array}{l}22 \\
32\end{array}$ & $\begin{array}{c}54 \\
86 \\
\text { (cisternal) }\end{array}$ \\
\hline
\end{tabular}

Mixed CSF is the fluid obtained after injection of air during PEG (see text).

$\mathrm{C}=$ cervical segments.

$\mathbf{T}=$ thoracic segments.

about 16 hours after the patient's last meal. Preparatory medication was given intramuscularly one half hour before the procedure started. The first few millilitres of CSF were kept for routine diagnostic purposes and then the first sample for this study was taken. The second ('mixed') sample was obtained at the end of the procedure, after all the air had been injected. In the fifth case, the presence of a complete spinal block was established by lumbar myelography, and a cervical myelography was performed on the same day. Fluid from both punctures was used for measurement of metabolites. However, since the amount of lumbar fluid available to us was very small, only 5-HIAA was measured in this specimen. The pertinent information about these patients is set out in Table 1.

A series of neurological patients, investigated by PEG at the same hospital, and without obstruction in CSF circulation, served as our controls (see Table 2).

Determination of the acids was done fluorometrically. Details of the procedure are given in a을 recent report from this laboratory (Papeschi andō McClure, 1971). Biochemical procedures were car- $?$

TABLE 2

HVA AND 5-HIAA CONCENTRATIONS IN DIFFERENT COMPARTMENTS OF CSF IN MAN, (IN SUBJECTS ASSUMED TO BE NORMAL IN RESPECT TO MONOAMINE METABOLISM) MEAN \pm SD (NUMBER OF MEASUREMENTS)

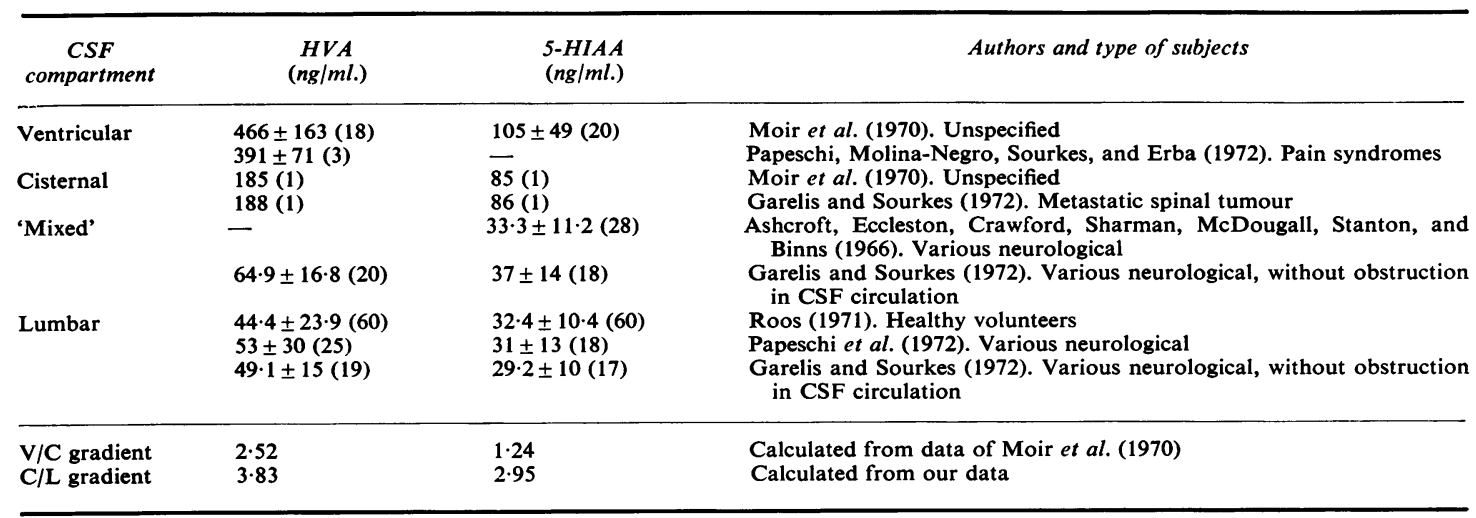

$\mathrm{V} / \mathrm{C}=$ ventricular/cisternal.

$\mathrm{C} / \mathrm{L}=$ cisternal/lumbar. 
ried out without previous knowledge of clinical information or PEG findings on the part of the analyst.

\section{RESULTS}

The analytical results for the HVA and 5-HIAA concentrations are given in Table 1. For purposes of comparison and discussion of certain points the 'normal' concentrations of HVA and 5-HIAA in various compartments of the CSF are presented in Table 2.

In case 1 a previous operation had demonstrated complete block of both foramina of Monro, so that both lateral ventricles were excluded from CSF circulation. The rest of the CSF compartment was found normal at PEG. HVA in the lumbar sample was $>2$ SD below the mean of our controls (cf. Table 2). The concentration in the mixed sample was even lower. On the contrary, both values were within the normal range for 5-HIAA.

Case 2 had been previously operated upon for a meningioma of the posterior fossa. During PEG, the ventricular system was visualized well, but no air passed into the basal cisterns. Obstruction of the V-A shunt was confirmed surgically; no sign of recurrence of the tumour was found. Lumbar concentrations of both acids were very high, corresponding, in fact, to cisternal values. On the other hand, the concentrations in the mixed sample were close to normal ventricular levels (cf. Table 2).

In case 3 no air was seen in the ventricular system, whereas some of the basal subarachnoid space was visualized. The neuroradiologist could not exclude the possibility that technical failure was responsible for this picture. HVA in the first sample was at the lower level of normal range; 5-HIAA was normal. Concentrations of both acids were much higher in the mixed sample. The relative increase was greater in the case of HVA.

Case 4 had multiple blocks at the thoracic level which, taken together, provided nearly complete obstruction. There was no evidence of blockage at higher levels. A few days after PEG, myelography showed the block to be complete. HVA was very low in the lumbar sample, but was within normal limits for the fluid collected after the injection of air. In contrast, concentrations of 5-HIAA in both samples were within the respective normal limits.
For case 5, 5-HIAA concentration on either side of the block seemed to be normal (cf. Table 2). The same was true for cisternal HVA.

\section{DISCUSSION}

The results of the present study throw light on the sites of origin in the CNS of monoamine metabolites. Thus, in case 4 , HVA is very low below the level of obstruction, but when lumbar fluid is mixed with CSF from higher compartments, the concentration increases greatly. This indicates that HVA originates above the block at the thoracic level. On the contrary, 5-HIAA concentration seems not to be affected by the obstruction in either sample, a result that suggests multiple sites of origin of this compound. Even in the case of complete block (case 5), lumbar 5-HIAA concentration is normal. Cisternal concentrations of both acids are very close to those of the only other case we could find in the literature where this measurement was made 0 (Table 2). To our knowledge, the present case 50 is the first where cisternal and lumbar concen- $₫$ trations of 5-HIAA have been determined in the same patient.

The results in case 1 indicate a further point 8 about the site of origin of the acidic metabolites. In this unusual case, the exclusion of both lateralce ventricles from CSF circulation results in very? low concentrations of HVA in both the lumbar and mixed specimens. This finding, therefore, suggests that most of the HVA in the CSF originates at the lateral ventricular level, and it is then likely that this HVA would come from neuronal structures adjacent to the lateral ventricle, mainly the striatum. This agrees with the pattern of distribution of dopamine in the brain (Hornykiewicz, 1966) and with the effect of nigrostriatal lesions on cisternal HVA (Papeschi, Sourkes, Poirier, and Boucher, 1971). Moreover, the sharp ventricular/cisternal gradient of concentration of HVA points to the same conclusion (Table 2). It is interesting that the gradient for HVA is reversed in this patient.

The concentrations of 5-HIAA in the fluids drawn from case 1 , unlike the situation with respect to HVA, are virtually unaffected by the block, so that it is evident that much 5-HIAA can be formed in lower parts of the CNS. The: ventricular/cisternal gradient of 5-HIAA concen- 
trations, very much smaller than in the case of HVA, also suggests that the acidic metabolite of serotonin can originate in substantial quantity below the ventricular level.

The high concentrations of HVA and 5-HIAA in both samples in case 2 are in good agreement with the findings in hydrocephalus (Ashcroft and Sharman, 1960; Andersson and Roos, 1965). This is probably due to defective transport of HVA and 5-HIAA from the CSF in hydrocephalus (Andersson and Roos, 1968).

Case 3 is more difficult to evaluate than the others. 5-HIAA is in the normal range in both specimens, but there is a relatively low concentration of HVA in the lumbar sample. This would be compatible with the existence of some obstruction, in conformity with the clinical diagnosis cited in Table 1 . However, the fact that the concentration of HVA undergoes a great increase after the injection of air is at variance with the possibility of a significant block between the 4th ventricle and the cisterna magna. As the patient was considered a poor surgical risk, the possibility of obstruction was not further investigated and the diagnosis was based on clinical grounds alone.

Obstruction of the circulation of CSF from the foramina of Monro down to the lower thoracic spine (cases 1 and 4) results in low lumbar HVA concentrations. In contrast with this, when the blockade creates a hydrocephalic situation (case 2) lumbar concentrations are very high. These facts obviously limit the suggestion by Curzon et al. (1971) that determination of lumbar HVA is of considerable help in diagnosing an obstruction of CSF circulation somewhere in the system. Furthermore, the possibility cannot be excluded in their study that concentrations of HVA and/or 5-HIAA might be low not only caudally to the partial cervical blocks, but also above.

Curzon et al. (1971) observed that, in their cases of spinal block, the lumbar 5-HIAA concentration was low. This was not true of our two cases.

Our results confirm the findings of Curzon et al. (1971) and of Bulat and Živcović (1971) on the dual origin of 5-HIAA in the lumbar fluid. However, information about the extent of the spinal contribution is lacking. Although this problem is best studied in experimental animals under controlled conditions, a rough estimate can be made from available data on man, as follows.

If we assume that the flux of active transport of the acidic metabolites out of the CSF is the same for both compounds, and that circulation of CSF affects them identically, then the difference in the cisternal/lumbar $(\mathrm{C} / \mathrm{L})$ gradients for HVA and 5-HIAA (Table 2) would be due to the fact that a portion of 5-HIAA comes from the spinal cord. On the basis of the assumptions made above, the $\mathrm{C} / \mathrm{L}$ gradient for HVA in our controls, 3.83 (Table 2), ought to apply equally to that portion of the lumbar 5-HIAA which is of cisternal origin. If the cisternal value for 5-HIAA in case 5 is regarded as a normal one, then $86 \div 3.83=22.4 \mathrm{ng} / \mathrm{ml}$., the portion of that 5-HIAA which would be contributed (by circulation and diffusion) to the lumbar CSF. The difference, therefore, between actual lumbar concentration of 5-HIAA and cisternal contribution gives a measure of 5-HIAA of spinal origin: $29 \cdot 2-22 \cdot 4=6.8 \mathrm{ng} / \mathrm{ml}$, or $6.8 / 29 \cdot 2 \times 100=23 \%$ of the actual lumbar concentration.

It should be pointed out that the data of Moir et al. (1970) on cisternal and lumbar concentrations in man do not agree with this estimate because their $\mathrm{C} / \mathrm{L}$ gradient for 5HIAA is higher than the gradient for HVA. This is due to the fact that the mean lumbar concentration of 5-HIAA for their controls $(19 \mathrm{ng} / \mathrm{ml}$.) is much lower than in our series or in Roos's healthy volunteers (see Table 2). However, if the $\mathrm{C} / \mathrm{L}$ gradients for the $\mathrm{dog}$, as given by Moir et al. (1970), are considered, the spinal contribution of 5-HIAA is calculated by the above process to be $37 \%$.

We thank Dr. R. Ethier of the Neuroradiology Department, Montreal Neurological Hospital, for his help on this study.

\section{REFERENCES}

Andersson, H., and Roos, B.-E. (1965). Acidic monoamine metabolites in cerebrospinal fluid of children with hydrocephalus. Acta Neurologica Scandinavica, 41, Suppl. 13, 149-151.

Andersson, H., and Roos, B. E. (1968). The effect of probenecid on the elimination from CSF of intraventricularly injected 5-hydroxyindoleacetic acid in normal and hydrocephalic dogs. Journal of Pharmacy and Pharmacology, 20, 879-881.

Andersson, H., and Roos, B.-E. (1969). 5-Hydroxyindoleacetic acid in cerebrospinal fluid of hydrocephalic children. Acta Paediatrica Scandinavica, 58, 601-608. 
Ashcroft, G. W., and Sharman, D. F. (1960). 5-Hydroxyindoles in human cerebrospinal fluids. Nature, 186, 10501051.

Ashcroft, G. W., Crawford, T. B. B., Eccleston, D., Sharman, D. F., MacDougall, E. J., Stanton, J. B., and Binns, J. K. (1966). 5-Hydroxyindole compounds in the cerebrospinal fluid of patients with psychiatric or neurological diseases. Lancet, 2, 1049-1052.

Bowers, M. B., Jr. (1972). Clinical measurements of central dopamine and 5-hydroxytryptamine metabolism: reliability and interpretation of cerebrospinal fluid acid monoamine metabolite measures. Neuropharmacology, 11, 101111.

Bulat, M., and Živcović, B. (1971). Origin of 5-hydroxyindoleacetic acid in the spinal fluid. Science, 173, 738-740.

Curzon, G., Gumbert, E. J. W., and Sharpe, D. M. (1971). Amine metabolites in the lumbar cerebrospinal fluid of humans with restricted flow of cerebrospinal fluid. Nature, New Biology, 231, 189-191.

Hornykiewicz, O. (1966). Dopamine (3-hydroxytyramine) and brain function. Pharmacological Reviews, 18, 925-964.
Moir, A. T. B., Ashcroft, G. W., Crawford, T. B. B., Eccleston, D., and Guldberg, H. C. (1970). Cerebral metabolites in cerebrospinal fluid as a biochemical approach to the brain. Brain, 93, 357-368.

Papeschi, R., and McClure, D. J. (1971). Homovanillic and 5-hydroxyindoleacetic acid in cerebrospinal fluid of depressed patients. Archives of General Psychiatry, 25, 354358.

Papeschi, R., Molina-Negro, P., Sourkes, T. L., and Erba, G. (1972). The concentration of homovanillic and 5-hydroxyindoleacetic acids in ventricular and lumbar CSF. Neurology (Minneapolis), 22, 1151-1159.

Papeschi, R., Sourkes, T. L., Poirier, L. J., and Boucher, R. (1971). On the intracerebral origin of homovanillic acid of the cerebrospinal fluid of experimental animals. Brain Research, 28, 527-533.

Roos, B. E. (1971). Metabolites of the monoamines in the cerebrospinal fluid. In Symposium Bel-Air, 4, Genève, 1970. Monoamines, Noyaux Gris Centraux et Syndrome de Parkinson, Publié sous la direction de J. de Ajuriaguerra et G. Gauthier. pp. 119-128. Georg: Geneva. 